\title{
Histone modification signature at myeloperoxidase and proteinase 3 in patients with anti-neutrophil cytoplasmic autoantibody-associated vasculitis
}

\author{
Jiajin Yang ${ }^{1 \dagger}$, Heng Ge ${ }^{1,4+}$, Caroline J. Poulton', Susan L. Hogan', Yichun Hu', Britta E. Jones ${ }^{1,2}$, \\ Candace D. Henderson ${ }^{1}$, Elizabeth A. McInnis ${ }^{1}$, William F. Pendergraft III', J. Charles Jennette ${ }^{1,2}$, \\ Ronald J. Falk ${ }^{1,2}$ and Dominic J. Ciavatta ${ }^{1,3^{*}}$
}

\begin{abstract}
Background: Anti-neutrophil cytoplasmic autoantibody (ANCA)-associated vasculitis (AAV) is a systemic autoimmune disease characterized by destructive vascular inflammation. Two prominent ANCA autoantigens are myeloperoxidase (MPO) and proteinase 3 (PR3), and transcription of MPO and PRTN3, the genes encoding the autoantigens, is associated with disease activity. We investigated whether patients with AAV have alterations in histone modifications, particularly those associated with transcriptional activation, at MPO and PRTN3.

Results: We identified a network of genes regulating histone modifications that were differentially expressed in AAV patients compared to healthy controls. We focused on four genes (EHMT1 and EHMT2, ING4, and MSL1) and found their expression correlated with expression of MPO and PRTN3. Methylation of histone H3K9, catalyzed by EHMT1 and EHMT2 and associated with gene silencing, was most depleted at MPO and PRTN3 in patients with active disease and the highest MPO and PRTN3 expression. Acetylation of histone H4K16, modified by complexes containing ING4 and MSL1 and associated with gene activation, was most enriched at MPO and PRTN3 in patients with active disease and the highest MPO and PRTN3 expression. Methylation at H3K4, a mark of transcriptional activation, was enriched at MPO and PRTN3 in patients and healthy controls.

Conclusions: MPO and PRTN3 in neutrophils of AAV patients with active disease have a distinct pattern of histone modifications, which implicates epigenetic mechanisms in regulating expression of autoantigen genes and suggests that the epigenome may be involved in AAV pathogenesis.
\end{abstract}

Keywords: ANCA-associated vasculitis, Epigenetics, Autoantigens, Gene expression, Neutrophils

\section{Background}

Anti-neutrophil cytoplasmic autoantibody (ANCA)-associated small-vessel vasculitis is an autoimmune disease characterized by autoantibodies directed against neutrophil granule proteins myeloperoxidase (MPO) or proteinase 3 (PR3). In vitro assays and in vivo mouse models

\footnotetext{
* Correspondence: dominic_ciavatta@med.unc.edu

${ }^{\dagger}$ Equal contributors

${ }^{1}$ UNC Kidney Center, Department of Medicine, Division of Nephrology and Hypertension, University of North Carolina at Chapel Hill, Chapel Hill, NC, USA ${ }^{3}$ Department of Genetics, University of North Carolina at Chapel Hill, 120 Mason Farm Road, Campus Box 7264, Chapel Hill, NC 27599, USA

Full list of author information is available at the end of the article
}

have established a pathogenic role for MPO-ANCA and suggest that PR3-ANCA is pathogenic [1-4]. Despite these data, the correlation of ANCA titers and disease status is less than perfect, with reports of $25 \%$ of patients having no relationship between clinical status and presence of ANCA [5]. In addition, naturally occurring autoantibodies to MPO in healthy individuals $[6,7]$ and multi-specific ANCA in ulcerative colitis [8] suggest that the characteristic vascular pathology requires additional component(s) beyond disrupted immunological tolerance to self. A prime candidate responsible for the pathology in patients with AAV is 
the neutrophil. Neutrophils are the major sources of PR3 and MPO, and vascular damage results from ANCA binding to these autoantigens inducing degranulation of primed neutrophils [1, 9-12]. This raises the question of whether neutrophils from healthy individuals compared to patients with AAV differ in a molecular signature, which could indicate a mechanism for neutrophil dysregulation in AAV.

A specific feature of mature peripheral blood neutrophils in patients with AAV is the presence of mRNA for PRTN3 and MPO [13]. Normally, these genes are transcribed in neutrophil progenitors residing in the bone marrow [14]. To explain the observation of aberrant autoantigen expression in AAV, we proposed that peripheral blood neutrophils from patients with AAV fail to silence or maintain silencing of PRTN3 and MPO due to reduced levels of the epigenetic modification histone $\mathrm{H} 3$ lysine 27 trimethylation (H3K27me3), associated with transcriptionally silent chromatin [15]. We hypothesize that in neutrophils of patients with AAV, a pattern of histone modifications at PRTN3 and MPO genes, including histone modifications associated with transcriptional activation, is associated with disease status, but which ones are altered among the myriad possibilities is unknown.

We probed expression data from AAV patients and healthy individuals to identify differentially expressed genes that encode proteins responsible for histone modifications associated with transcriptional activity. We determined whether the levels of histone modifications at PRTN3 and MPO differed between AAV patients and healthy individuals. Interestingly, measuring the levels of several histone modifications at PRTN3 and $M P O$ revealed an epigenetic signature that is related to gene expression and AAV disease status.

\section{Results}

Analysis of microarray expression data to identify genes that regulate chromatin modifications

Previous studies demonstrated that $M P O$ and PRTN3 transcripts are aberrantly elevated in patients with AAV compared to healthy controls, and their expression levels are highly correlated [13]. Later, epigenetic differences were identified in patients with AAV and the transcriptional regulation of $M P O$ and PRTN3 involved epigenetic control [15]. To identify additional epigenetic mechanisms that may be faulty in patients with AAV, we analyzed microarray expression data from 25 peripheral blood leukocyte samples of AAV patients and 16 samples from healthy controls (Additional file 1: Table S1). We found 11,444 genes to be differentially regulated ( $\geq$ \pm 1.2 -fold and $p<0.05)$ in AAV patients. Principal component analysis (PCA) revealed the gene expression profiles in AAV patients cluster separately from expression profiles of healthy controls (Fig. 1a). The list of differentially expressed genes was filtered using Ingenuity Pathway Analysis (IPA) to identify genes associated with chromatin modifications. Among these were genes involved in controlling epigenetic marks of transcriptional activation and transcriptional silencing (Table 1). IPA also revealed that 30 of these genes were involved in a network with connections to histone, histone $\mathrm{H} 3$ and/or histone H4 (Fig. 1b). This discovery of differentially expressed genes responsible for regulatory histone modifications warranted further investigation of epigenetic mechanisms in AAV patients.

\section{Expression of histone modifying genes}

From our filtered list of differentially expressed genes, we evaluated two genes (Euchromatic histone-lysine $N$ methyltransferase 1 and 2, EHMT1/GLP and EHMT2/

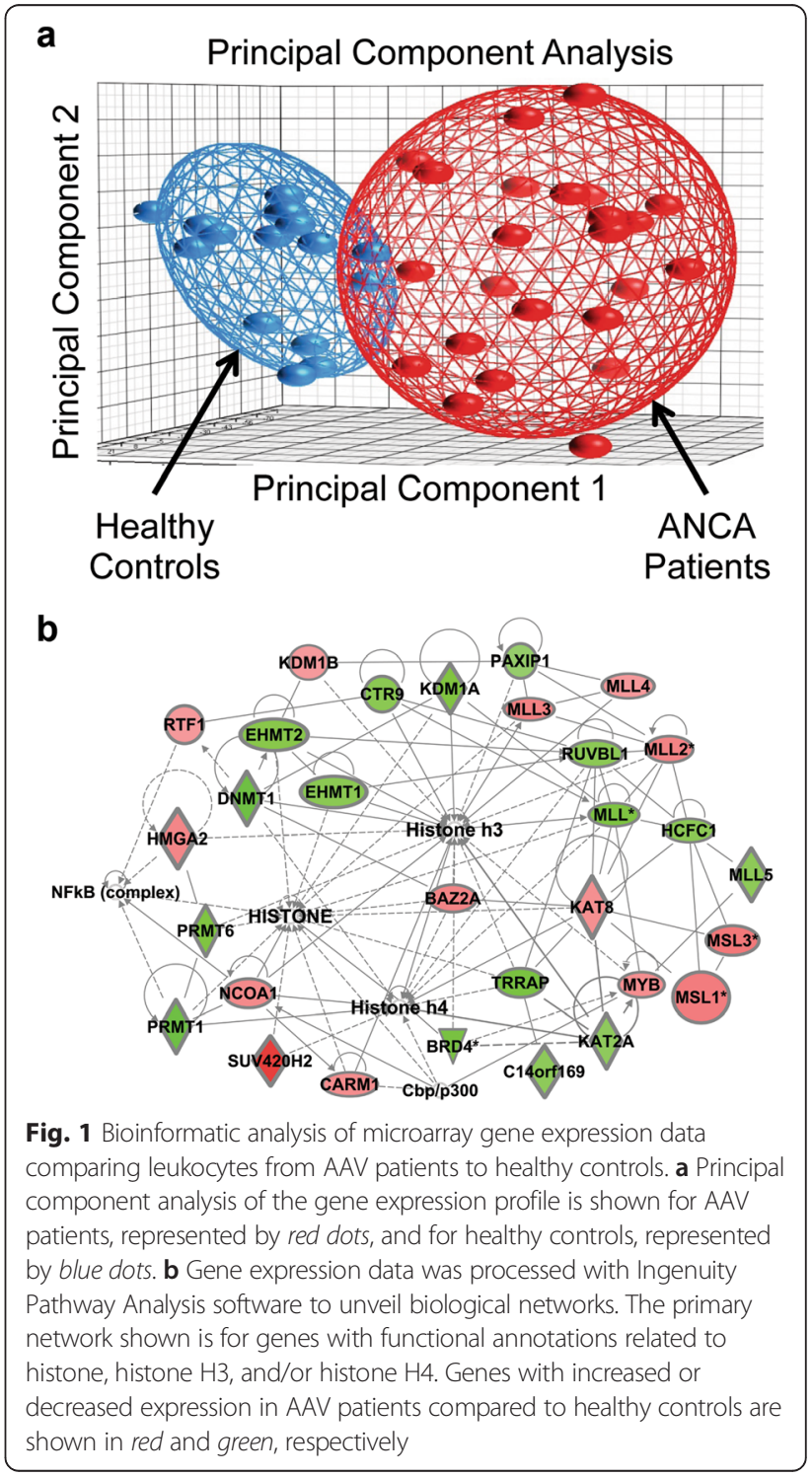


Table 1 Differentially expressed genes in patients with ANCA-associated vasculitis compared to healthy controls regulating histone post-translational modifications and DNA methylation

\begin{tabular}{|c|c|c|c|c|}
\hline Gene symbol & Fragment name & Entrez gene name & ANCA/HC $p$ & ANCA/HC fold change \\
\hline \multicolumn{5}{|c|}{ Histone H4K16, H4K5, H4K12 acetylation } \\
\hline MSL3 & 207551_s_at & male-specific lethal 3 homolog & 0.0002 & 1.65 \\
\hline MSL1 & 224765_at & male-specific lethal 1 homolog & $<0.0001$ & 1.60 \\
\hline KAT8 & 221820_s_at & lysine acetyltransferase 8 & 0.0187 & 1.38 \\
\hline BRD4 & 226052_at & bromodomain containing 4 & 0.0003 & 1.38 \\
\hline ING4 & 218234_a & inhibitor of growth family, member 4 & $<0.0001$ & -2.05 \\
\hline \multicolumn{5}{|c|}{ Histone H3K4 methylation } \\
\hline MLL3 & 222415_at & myeloid/lymphoid or mixed-lineage leukemia 3 & $<0.0001$ & 1.53 \\
\hline MLL2 & 231974_at & myeloid/lymphoid or mixed-lineage leukemia 2 & 0.0003 & 1.51 \\
\hline MLL4 & 203419_at & myeloid/lymphoid or mixed-lineage leukemia 4 & 0.0107 & 1.26 \\
\hline RTF1 & 212302_at & Rtf1, Paf1/RNA polymerase II complex component & 0.0409 & 1.24 \\
\hline$B C O R$ & 223566_s_at & BCL6 corepressor & $<0.0001$ & -1.74 \\
\hline KDM1A & 212348_s_at & lysine-specific demethylase $1 \mathrm{~A}$ & 0.0002 & -1.57 \\
\hline C14orf169 & 219526_at & lysine-specific demethylase NO66 & 0.0002 & -1.34 \\
\hline \multicolumn{5}{|c|}{ Histone H3K14 acetylation } \\
\hline BRD4 & 226052_at & bromodomain containing 4 & 0.0003 & 1.38 \\
\hline \multicolumn{5}{|c|}{ Histone H3K36 methylation } \\
\hline NSD1 & 225654_at & nuclear receptor binding SET domain protein 1 & 0.0208 & 1.34 \\
\hline$B C O R$ & 223566_s_at & BCL6 corepressor & $<0.0001$ & -1.74 \\
\hline C14orf169 & 219526_at & lysine-specific demethylase N066 & 0.0002 & -1.34 \\
\hline \multicolumn{5}{|c|}{ Histone H3K9 methylation } \\
\hline EHMT1 & 222873_s_at & euchromatic histone-lysine N-methyltransferase 1 & 0.0084 & -1.41 \\
\hline EHMT2 & 202326_at & euchromatic histone-lysine N-methyltransferase 2 & 0.0013 & -1.44 \\
\hline$A R I D 4 B$ & 212591_at & AT rich interactive domain 4B (RBP1-like) & $<0.0001$ & -1.51 \\
\hline \multicolumn{5}{|c|}{ Histone H4K20 methylation } \\
\hline$A R I D 4 B$ & 212591_a & AT rich interactive domain 4B (RBP1-like) & $<0.0001$ & -1.51 \\
\hline \multicolumn{5}{|c|}{ DNA methylation } \\
\hline DNMT1 & 201697_s_at & DNA (cytosine-5-)-methyltransferase 1 & $<0.0001$ & -2.03 \\
\hline
\end{tabular}

G9a) that regulate histone H3K9 methylation, associated with transcriptionally silent chromatin, and two genes (male sex lethal 1 homolog, MSL1 and insulin growth factor, ING4) that regulate histone acetylation, associated with transcriptionally active chromatin. We chose EHMT1/GLP and EHMT2/G9a to address whether the H3K9me2 pathway was involved in epigenetic silencing of MPO and PRTN3 expression. We investigated genes that regulate histone acetylation as a mechanistic explanation for increased expression of MPO and PRTN3 in patients with AAV. MSL1 is a subunit of a human acetyltransferase (HAT) complex that acetylates histone H4K16 [16]. ING4 plays a complex role in gene regulation [17]. It associates with HBO1 HAT complex [18], but ING4 can also interact with NFkB and enhance HDAC-1 levels at promoters [19]. Microarray analysis revealed expression of EHMT1/GLP, and EHMT2/G9a was significantly depleted in leukocytes from AAV patients compared to healthy controls, while expression of MSL1 was statistically elevated (Table 1). Interestingly, leukocytes from AAV patients had reduced ING4 expression compared to healthy controls. Expression levels of EHMT2/G9a and ING4 negatively and MSL1 positively correlated with PRTN3 and MPO mRNA levels (Table 2). EHMT1/GLP did not show a significant correlation with PRTN3 and MPO mRNA.

Quantitative RT-PCR (qRT-PCR), to confirm the microarray results, was used to measure mRNA levels for MPO, PRTN3, EHMT1 and 2, MSL1, and ING4 in total leukocytes from a separate cohort of 20 healthy controls and 80 AAV patients (Additional file 2: Table S2). The patients were divided evenly into MPO-ANCA 
Table 2 Correlation of expression levels of PRTN3 and MPO with genes associated with histone modifications

\begin{tabular}{|c|c|c|c|c|}
\hline \multirow[b]{2}{*}{ Gene name } & \multicolumn{2}{|l|}{ Microarray } & \multicolumn{2}{|l|}{ Quantitative RT-PCR } \\
\hline & $\begin{array}{l}\text { Correlation with PRTN3 } \\
\text { expression }\end{array}$ & $\begin{array}{l}\text { Correlation with MPO } \\
\text { expression }\end{array}$ & $\begin{array}{l}\text { Correlation with PRTN3 } \\
\text { expression }\end{array}$ & $\begin{array}{l}\text { Correlation with MPO } \\
\text { expression }\end{array}$ \\
\hline$\overline{M P O}$ & $\begin{array}{l}r=0.840 \\
p<0.0001\end{array}$ & & $\begin{array}{l}r=0.920 \\
p<0.0001\end{array}$ & \\
\hline EHMT1 & $\begin{array}{l}r=-0.213 \\
p=0.182\end{array}$ & $\begin{array}{l}r=-0.148 \\
p=0.357\end{array}$ & $\begin{array}{l}r=-0.436 \\
p<0.0001\end{array}$ & $\begin{array}{l}r=-0.391 \\
p<0.0001\end{array}$ \\
\hline EHMT2 & $\begin{array}{l}r=-0.461 \\
p=0.0024\end{array}$ & $\begin{array}{l}r=-0.537 \\
p=0.0003\end{array}$ & $\begin{array}{l}r=-0.396 \\
p<0.0001\end{array}$ & $\begin{array}{l}r=-0.400 \\
p<0.0001\end{array}$ \\
\hline MSL1 & $\begin{array}{l}r=-0.463 \\
p=0.0006\end{array}$ & $\begin{array}{l}r=-0.412 \\
p=0.0046\end{array}$ & $\begin{array}{l}r=-0.469 \\
p<0.0001\end{array}$ & $\begin{array}{l}r=-0.409 \\
p<0.0001\end{array}$ \\
\hline ING4 & $\begin{array}{l}r=-0.515 \\
p=0.0023\end{array}$ & $\begin{array}{l}r=-0.433 \\
p=0.0075\end{array}$ & $\begin{array}{l}r=-0.516 \\
p<0.0001\end{array}$ & $\begin{array}{l}r=-0.477 \\
p<0.0001\end{array}$ \\
\hline
\end{tabular}

and PR3-ANCA serotypes, and each ANCA serotype was divided into 20 remission patients $(B V A S=0)$ and 20 active patients (BVAS $\geq 3$ ). Quantitative RT-PCR revealed that EHMT1, EHMT2, and ING4 were statistically reduced in leukocytes from AAV patients $(n=80)$ compared to healthy controls $(n=20)$. MSL1 was statistically elevated in AAV patients (Fig. 2a). As observed previously, in this set of patient samples, expression of $M P O$ and PRTN3 was highly correlated. Expression levels of EHMT1, EHMT2, and ING4 negatively and MSL1 positively correlated with PRTN3 (ANCA $351.38 \pm 608.75$ versus $\mathrm{HC} 10.01 \pm 8.98, p<0.0001$ ) and $M P O$ (ANCA $643.41 \pm 1106.44$ versus $\mathrm{HC} 36.83 \pm 18.27, p<0.0001$ ) mRNA levels (Table 2). These data suggest an association exists between genes that regulate histone modifications linked to transcriptional status and the expression MPO and PRTN3.

This association is further supported when comparing the expression level of EHMT1 and 2, ING4, and MSL1 in healthy controls to AAV patients with active disease (BVAS $\geq 3$ ) and high $M P O$ and PRTN3 mRNA (two standard deviations above the mean for healthy controls), and AAV patients in remission $(B V A S=0)$ with low MPO and PRTN3 mRNA (no different from healthy controls). Compared to healthy controls, the expression of EHMT1 and 2, ING4, and MSL1 changes more dramatically in AAV patients with active disease and elevated MPO and PRTN3 mRNA than in AAV patients in remission with low $M P O$ and PRTN3 mRNA (Fig. 2b). These relationships suggest that expression of genes that regulate histone modifications is associated with disease activity.

A recent report describes a link between steroid therapy and expression changes of autoantigen genes [20]; therefore, it is conceivable that the expression differences of histone modifying genes are a response to therapy. However, in the cohort of patients used to measure expression by qRT-PCR, there is no significant difference in the expression of the four histone-modifying genes, EHMNT1, EHMT2, ING4, MSL1, in patients in remission and receiving corticosteroids and patients in remission receiving another therapy, or between patients in remission receiving no therapy and patients receiving another therapy. Only the expression of MSL1 is significantly different (increased) in remitting patients on corticosteroids compared to remitting patients receiving no therapy (Additional files 2 and 3: Table S2 and Figure S1). This suggests that corticosteroid treatment alone does not explain changes in gene expression of histonemodifying genes.

The altered expression of the four histone-modifying genes detected in total leukocytes raises the question of which cell types in the peripheral blood of patients with AAV are responsible for the differential gene expression. To test this, we isolated RNA from purified monocytes and neutrophils and performed qRT-PCR to measure expression of EHMT1, EHMT2, ING4, and MSL1. In general, patients with AAV expressed less EHMT1 and EHMT2 compared to healthy controls in both monocytes and neutrophils (Fig. 3a, b, respectively). MSL1 mRNA was significantly elevated in neutrophils (Fig. 3b) from patients compared to healthy controls, but was not significantly elevated in monocytes (Fig. 3a). Although the level of ING4 message in monocytes and neutrophils tended to be lower in patients than healthy controls, the difference was not significant. These results point to both monocytes and neutrophils as sources of the reduced expression of EHMT1 and EHMT2, while the increased expression of MSL1 in patients appears to occur predominately in neutrophils.

Reduced levels of histone mark regulating transcriptional repression in patients with ANCA-associated vasculitis Since we found decreased expression of EHMT1 and 2, we tested whether there is a reduction in $\mathrm{H} 3 \mathrm{~K} 9 \mathrm{me} 2$ at $M P O$ and PRTN3 genes. Chromatin immunoprecipitation 


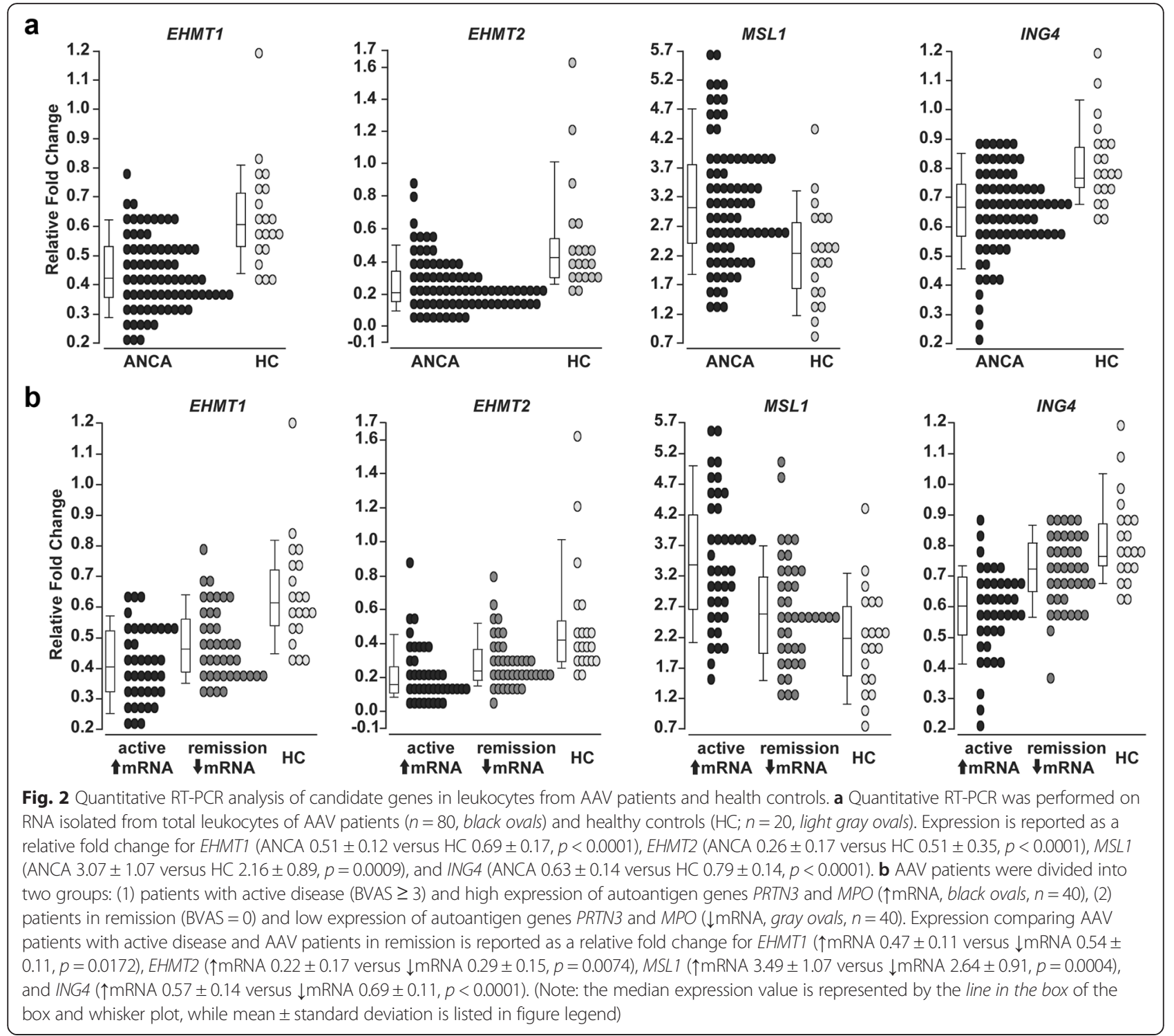

(ChIP) was performed on neutrophils isolated from 15 AAV patients and 21 healthy controls (Additional file 4: Table S3). We detected a modest but significant decrease in the level of H3K9me2 at both the MPO and PRTN3 gene promoters in AAV patients compared to healthy controls (Fig. 4a). At a transcriptionally silent gene in neutrophils, $M Y O-D$, there was a similar enrichment for H3K9me2 between AAV patients and healthy controls. As described for the expression of EHMT1 and 2 compared to MPO and PRTN3 expression, H3K9me2 was more dramatically depleted at PRTN3 and MPO promoter in AAV patients with active disease and high $M P O$ and PRTN3 mRNA compared to controls, but in AAV patients in remission with low $M P O$ and PRTN3 mRNA, H3K9me2 does not differ from the healthy controls (Fig. 5a). We detected a modest but significant negative correlation between H3K9me2 levels at PRTN3 and MPO promoters and expression of MPO and PRTN3 $(r=-0.346, p=0.0386 M P O$ prm and $M P O$ expression; $r=-0.373, p=0.0252$ PRTN3 prm and PRTN3 expression) (Table 3). This inverse relationship is consistent with a role for this modification in silencing $M P O$ and PRTN3 in mature neutrophils, and the $\mathrm{H} 3 \mathrm{~K} 9 \mathrm{me} 2$ silencing pathway may be disrupted in AAV patients.

\section{Elevated levels of histone modifications regulating transcriptional activation in patients with ANCA- associated vasculitis}

In light of our expression data, we wondered if marks coincident with transcriptional activation were elevated in AAV patients. Because of increased expression of 


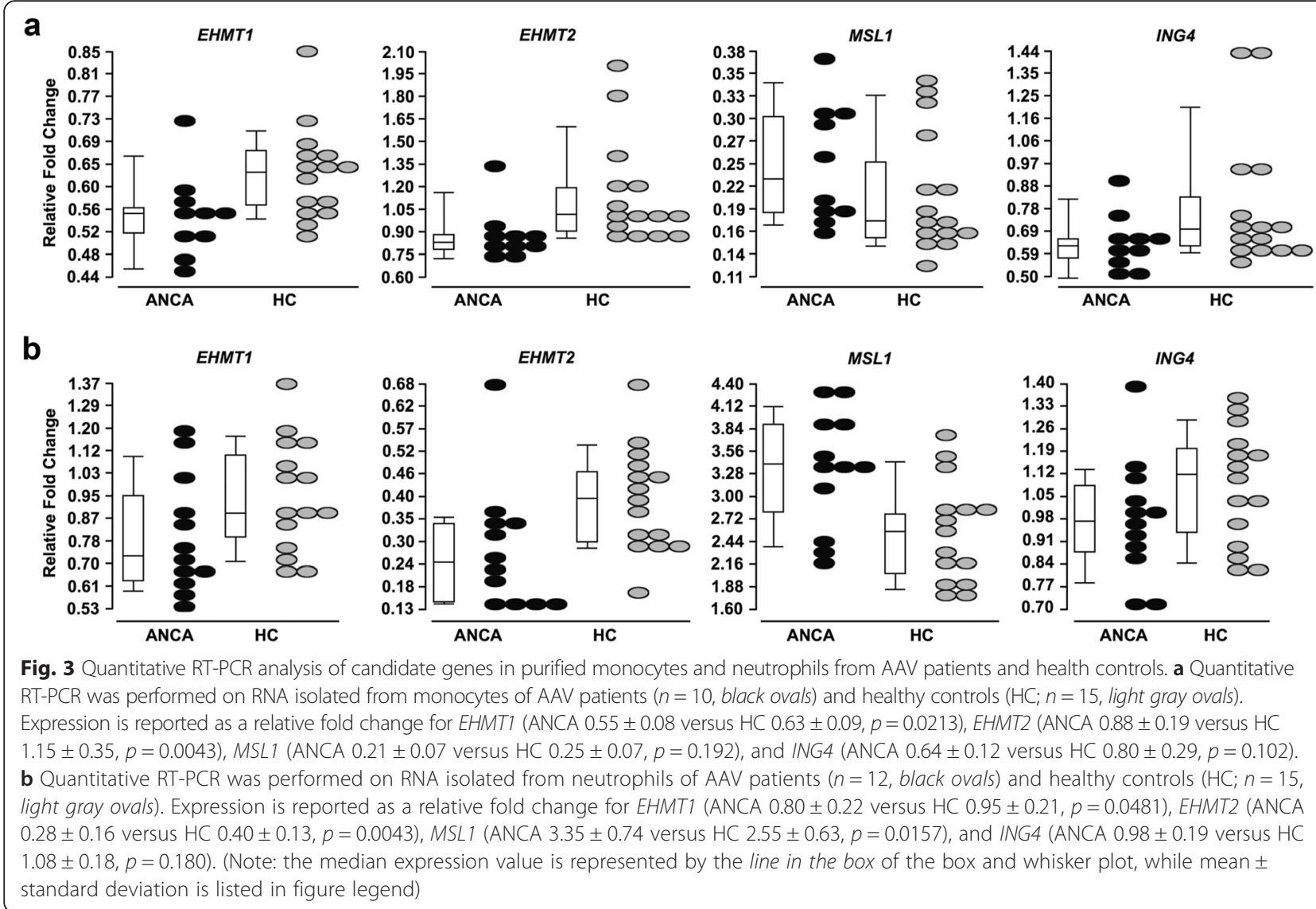

MSL1 (encoding a histone H4 HAT) in AAV patients, we used ChIP to examine the level of H4K16 acetylation (H4K16ac) at MPO and PRTN3 promoters. H4K16ac was significantly elevated in patients $(n=25)$ compared to healthy controls $(n=20)$, but not different between patients and controls at the FCGR3B gene (Fig. 4b). The level of H4K16ac at the PRTN3 promoter showed a modest correlation with PRTN3 expression $(r=0.303, p=0.0563)$, and H4K16ac at the $M P O$ promoter showed a modest, significant correlation with $M P O$ expression $(r=0.427, p=0.0058)$ (Table 3). Similar to the relationship described above for the level of H3K9me2 and MPO and PRTN3 expression, the level of H4K16ac was markedly higher in AAV patients with active disease and high $M P O$ and PRTN3 expression versus patients in remission with low MPO and PRTN3 expression (Fig. 5b).

Because genes involved in $\mathrm{H} 3$ acetylation were increased in AAV patients (Table 1), we performed ChIP for H3K9,14ac. Low levels of this modification were detected at PRTN3 and MPO promoters and not different between AAV patients and healthy controls (Additional file 5: Figure S2a). This was surprising given that preliminary data that indicated $\mathrm{H} 3 \mathrm{~K} 9,14 \mathrm{ac}$ levels were closely associated with expression of $M P O$ and PRTN3 in HL60 cells (Additional file 5: Figure $\mathrm{S} 2 \mathrm{~b}$ ); however, this underscores the idea that regulatory mechanisms for the same genes may differ in cell lines compared to primary human cells.

Several mixed-lineage leukemia genes (MLL2, 3, and 4) were expressed more in AAV patients compared to healthy controls. Since the MLLs regulate transcriptional activation and catalyze methylation of H3K4, we measured H3K4me2 levels. ChIP for H3K4me2 revealed that PRTN3 and MPO promoters were highly enriched for this modification in both AAV patients $(n=8)$ and healthy controls $(n=9)$ (Fig. 4c). Because the promoters of MPO and PRTN3 in healthy controls have high levels (slightly higher than the promoters in ANCA patients) of H3K4me2, these genes may be in a transcriptionally competent state, ready to respond at the transcriptional level to stimuli, but are maintained silent by repressive histone modifications. Figure $5 \mathrm{c}$ summarizes the ChIP data for three different histone modifications and illustrates an epigenetic signature at MPO and PRTN3 genes related to disease status and autoantigen expression. 

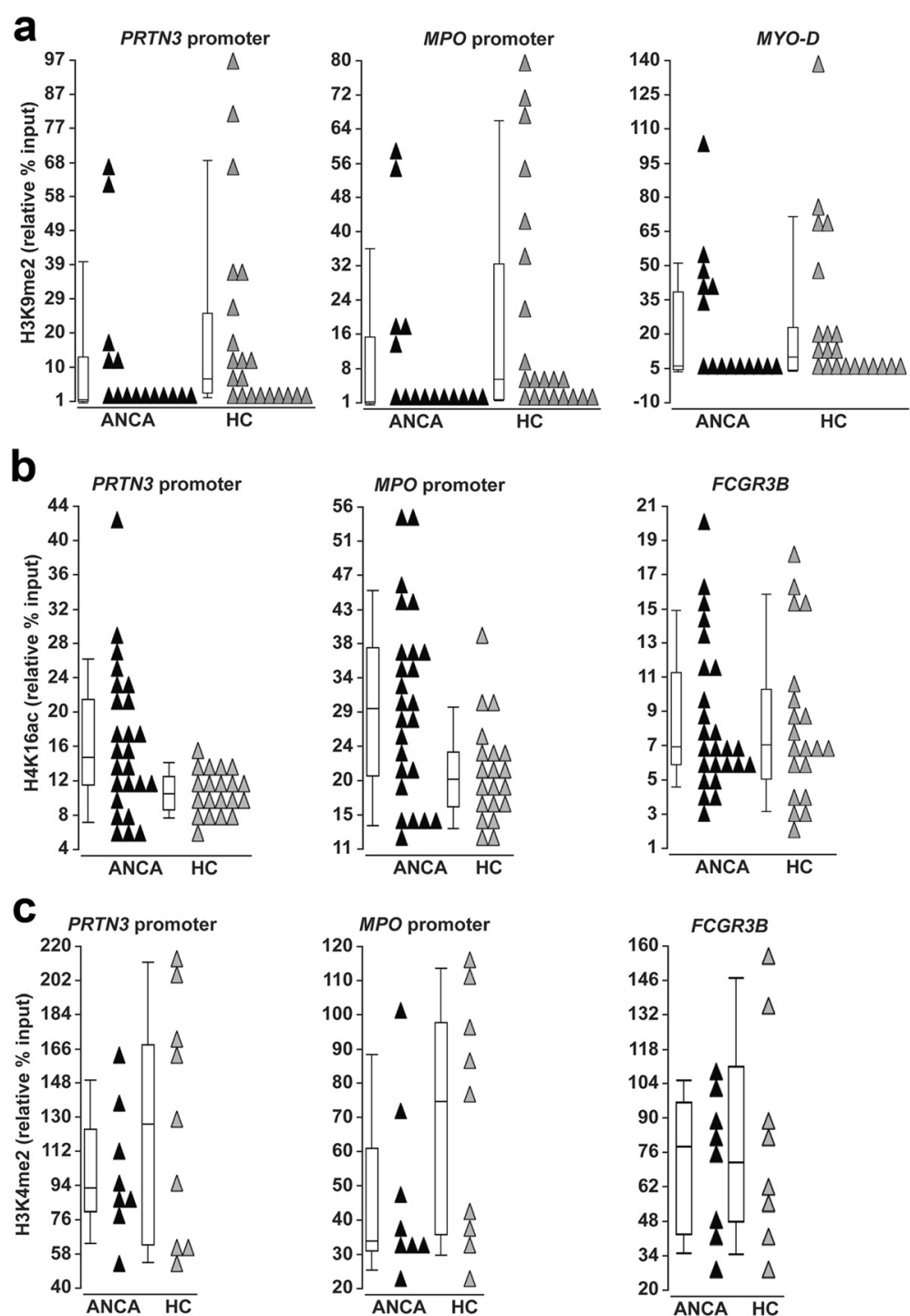

Fig. 4 Chromatin immunoprecipitation (ChIP)-quantitative PCR analysis for histone modifications at autoantigen genes in AAV patients and healthy controls. a ChIP-qPCR was performed on AAV patients (ANCA, black triangles, $n=15$ ) and healthy controls (HC; gray triangles, $n=21$ ) for H3K9me2. The level of the H3K9me2 modification is reported as relative percent of input at the PRTN3 promoter (ANCA 12.44 $\pm 22.10, \mathrm{HC} 21.17 \pm 28.55 ; p=0.0192$ ), MPO promoter (ANCA 11.37 \pm 19.01, HC $20.01 \pm 28.55 ; p=0.0247$ ), and a control gene, MYO-D (ANCA 21.42 \pm 28.78, HC 23.63 $\pm 35.53 ; p=0.702$ ). b ChIP-qPCR for H4K16ac was performed on AAV patients (ANCA, black triangles, $n=25$ ) and healthy controls (HC; gray triangles, $n=20$ ). The level of the H4K16ac modification is reported as relative percent of input at the PRTN3 promoter (ANCA 17.10 $\pm 9.14, \mathrm{HC} 10.83 \pm 2.73 ; p=0.0116$ ), MPO promoter (ANCA $30.30 \pm 12.89, \mathrm{HC} 21.06 \pm 6.67 ; p=0.0132$ ) and at a control gene, FCGR3B (ANCA 9.19 \pm 4.74, HC 8.83 $\pm 5.14, p=0.864$ ). $\mathbf{c}$ ChIP-qPCR for H3K4me2 was performed on AAV patients (ANCA, black triangles, $n=8$ ) and healthy controls ( $\mathrm{HC}$, gray triangles, $n=8$ ). The level of the H3K4me2 modification is reported as relative percent of input at the PRTN3 promoter (ANCA 50.68 \pm 18.15, HC $63.78 \pm 32.86, p=0.532$ ), MPO promoter (ANCA $24.17 \pm 14.80, \mathrm{HC} 36.09 \pm 18.88, p=0.136$ ), and at a control gene, FCGR3B (ANCA $74.01 \pm 30.26, \mathrm{HC} 82.74 \pm 46.52, p=0.878$ ) (Note: the level of the indicated histone modification was calculated using raw $\mathrm{Ct}$ values from qPCR of diluted input sample. The median expression value is represented by the line in the box of the box and whisker plot, while mean \pm standard deviation is listed in figure legend)

\section{Discussion}

\section{Differential expression of genes encoding histone-} modifying enzymes

We explored whether patients with AAV had changes in expression of genes encoding factors that establish and maintain chromatin modifications. Analysis of microarray data comparing AAV patients to healthy controls revealed a network of genes related to chromatin modifications. Quantitative RT-PCR confirmed differential expression of EHMT1/GLP and EHMT2/G9a, encoding H3K9 methyltransferases, and MSL1 and ING4, encoding H4K16 acetyltransferases. The expression of these four genes correlated with expression of MPO and PRTN3, and the expression of $M P O$ and PRTN3 is strongly correlated. 

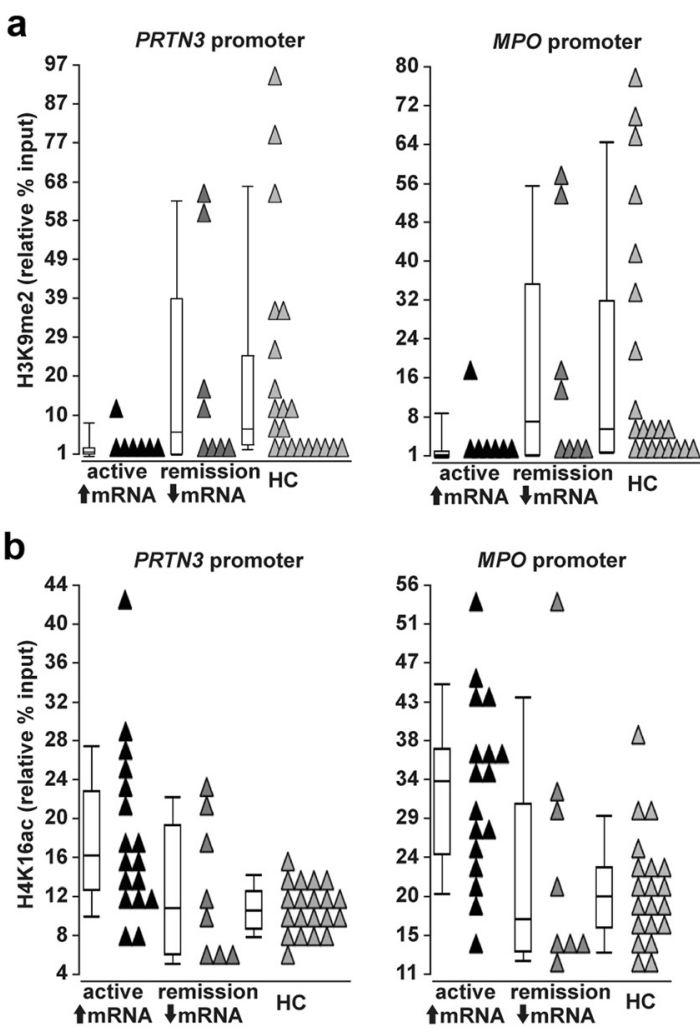

C

Histone Modifications at Autoantigen Genes

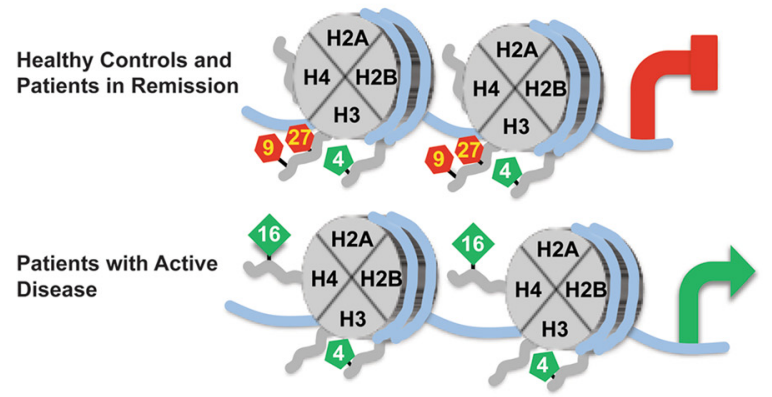

Fig. 5 ChIP-quantitative PCR analysis for histone modifications at autoantigen genes in ANCA-patients with high and low PRTN3 and MPO expression. a The level of H3K9me2 is reported as relative percent input for AAV patients with active disease (BVAS $\geq 3$ ) and high expression of PRTN3 and MPO ( $\uparrow m R N A$, black triangles, $n=7$ ) and for healthy controls ( $H C$; light gray triangles, $n=21$ ) at the PRTN3 promoter ( $\uparrow m R N A 3.41 \pm 5.20, H C 21.17 \pm 28.55 ; p$ $=0.0068$ ) and the MPO promoter ( $\uparrow m R N A 3.34 \pm 6.02, \mathrm{HC} 20.01 \pm 26.00 ; p=0.0058$ ). The level of H3K9me2 is reported as relative percent input for AAV patients in remission (BVAS $=0)$ and low expression of PRTN3 and MPO ( $\downarrow$ mRNA, gray triangles, $n=8)$ for healthy controls at the PRTN3 promoter ( $\downarrow$ mRNA $20.33 \pm 28.30, \mathrm{HC} 21.17 \pm 28.55 ; p=0.294)$ and at the MPO promoter ( $\downarrow$ mRNA $18.41 \pm 23.88, \mathrm{HC} 20.01 \pm 26.00 ; p=0.393)$. $\mathbf{b}$ The level of H4K16ac is reported as relative percent input for AAV patients with active disease (BVAS $\geq 3$ ) and high expression of PRTN3 and MPO ( $\uparrow m R N A$, black triangles, $n=17$ ) and for healthy controls ( $H C$; light gray triangles, $n=20$ ) at the PRTN3 promoter ( $\uparrow$ mRNA 19.12 $\pm 9.31, H C 10.83 \pm 2.73 ; p=0.0009)$ and the MPO promoter ( $\uparrow m R N A 33.26 \pm 11.03, \mathrm{HC} 21.56 \pm 6.67 ; p=0.0006)$. The level of H4K16ac is reported as relative percent input for AAV patients in remission (BVAS $=0)$ and low expression of PRTN3 and MPO ( $\downarrow$ mRNA, gray triangles, $n=8)$ for healthy controls at the PRTN3 promoter $(\downarrow m R N A 12.81 \pm$ $7.55, \mathrm{HC} 10.83 \pm 2.73 ; p=0.939$ ) and at the MPO promoter ( $\downarrow$ mRNA $24.02 \pm 15.02, \mathrm{HC} 21.56 \pm 6.67 ; p=0.859$ ). (Note: the level of the indicated histone modification was calculated using raw Ct values from GPCR of diluted input sample. The median expression value is represented by the line in the box of the box and whisker plot, while mean \pm standard deviation is listed in figure legend.) $\mathbf{c}$ Illustration depicts a model for modifications of histone tails at promoters of PRTN3 and MPO in healthy controls and AAV patients in remission (top), and in AAV patients with active disease (bottom)

Furthermore, expression of EHMT1 and 2, MSL1 and ING4 differed more between healthy controls and AAV patients with active disease $(B V A S \geq 3)$ and the highest levels of $M P O$ and PRTN3 mRNA than between healthy controls and AAV patients in remission $(B V A S=0)$ with low levels of $M P O$ and PRTN3 mRNA. 
Table 3 Correlation of PRTN3 and MPO expression with H3K9me2 and H4K16ac levels at PRTN3 and MPO promoter

\begin{tabular}{|c|c|c|c|c|}
\hline \multirow[b]{2}{*}{ Gene name } & \multicolumn{2}{|c|}{ H3K9me2 $(N=36)$} & \multicolumn{2}{|c|}{$\mathrm{H} 4 \mathrm{~K} 16 \mathrm{ac}(N=40)$} \\
\hline & $\begin{array}{l}\text { Correlation } \\
\text { with PRTN3 } \\
\text { expression }\end{array}$ & $\begin{array}{l}\text { Correlation } \\
\text { with MPO } \\
\text { expression }\end{array}$ & $\begin{array}{l}\text { Correlation } \\
\text { with PRTN3 } \\
\text { expression }\end{array}$ & $\begin{array}{l}\text { Correlation } \\
\text { with MPO } \\
\text { expression }\end{array}$ \\
\hline PRTN3 promoter & $\begin{array}{l}r=-0.373 \\
p=0.0252\end{array}$ & & $\begin{array}{l}r=-0.303 \\
p=0.0563\end{array}$ & \\
\hline MPO promoter & & $\begin{array}{l}r=-0.346 \\
p=0.0386\end{array}$ & & $\begin{array}{l}r=-0.427 \\
p=0.0058\end{array}$ \\
\hline
\end{tabular}

\section{Histone modifications at autoantigen genes associated with disease activity}

We also explored in patients with AAV whether the histone modifications regulated by these differentially expressed genes were altered at MPO and PRTN3 genes. In neutrophils from patients with high $M P O$ and PRTN3 mRNA and active disease, the MPO and PRTN3 promoters were depleted for H3K9me2 and enriched for H4K16ac compared to healthy controls and patients in remission. In contrast, another histone modification that is associated with gene activation showed similar levels between AAV patients and healthy controls (H3K9,14ac), while H3K4me2 levels were enriched at MPO and PRTN3 in patients and healthy controls. These data and our previous ChIP studies on neutrophils demonstrate that $M P O$ and PRTN3 genes in healthy controls and AAV patients in remission are enriched for silencing marks H3K27me3 and $\mathrm{H} 3 \mathrm{~K} 9 \mathrm{me} 2$ and the activation mark H3K4me2. In contrast, $M P O$ and PRTN3 genes in active AAV patients have reduced levels of $\mathrm{H} 3 \mathrm{~K} 27 \mathrm{me} 3$ and $\mathrm{H} 3 \mathrm{~K} 9 \mathrm{me} 2$, maintain enrichment of $\mathrm{H} 3 \mathrm{~K} 4 \mathrm{me} 2$, and gain the activation mark H4K16ac.

Two results from the expression analysis were unexpected. First, we did not identify changes in gene expression in AAV patients for genes encoding Polycomb Repressor Complex-2 (PRC2) subunits. However, the absence of changes in PRC2 genes is consistent with a model we proposed in which the deficit in H3K27me3 genes results from a failure to recruit PRC2 to $M P O$ and PRTN3 via RUNX3, or histone demethylase activity [15]. Second, although our initial measurements of H3K9me2 showed a modest decrease in AAV patients, we found reduced expression of EHMT1/GLP and EHMT/G9a in patients. Reexamining the ChIP data for $\mathrm{H} 3 \mathrm{~K} 9 \mathrm{me} 2$ revealed the modification was more dramatically depleted at $M P O$ and PRTN3 in active AAV patients with high autoantigen gene expression. This suggests that in addition to $\mathrm{H} 3 \mathrm{~K} 27 \mathrm{me}$, H3K9me2 and the factors that catalyze this histone mark contribute to the transcriptional silencing of ANCA autoantigen genes in healthy individuals and AAV patients in remission.
H3K27me3 and H3K4me2 enriched at autoantigen genes in PMNs from healthy individuals and AAV patients in remission

The levels of both H3K27me3 and H3K4me2 at MPO and PRTN3 genes raises the intriguing possibility that in healthy controls and remitting patients, these genes are maintained in a bivalent epigenetic state. A model to explain the function of this chromatin state proposes that bivalent genes are suppressed in pluripotent cells but poised for activation later in development [21, 22]. Genome-wide chromatin studies have detected bivalent domains in differentiated cells, particularly of the hematopoietic lineage $[23,24]$. An exciting possibility is that in peripheral blood neutrophils, the PRTN3 and $M P O$ genes adopt a bivalent mode of transcriptional control and exist as transcriptionally poised genes. Although a poised chromatin state is consistent with studies demonstrating inducible transcriptional activity in neutrophils [25-29], it is possible that the apparent bivalent signature represents a mosaic between neutrophils with H3K27me3 and neutrophils with H3K4me2. If a population of neutrophils contains a mixture of cells with either one of these two histone modifications, it would suggest that neutrophils with H3K4me2 employ another silencing mechanism; distinguishing these possibilities warrants further investigation.

\section{Other potential cell types responsible for differential expression of autoantigen genes}

The model of epigenetic control we propose assumes that the elevated expression of MPO and PRTN3 in AAV is primarily from neutrophils. Others have reported increased $M P O$ and PRTN3 expression in monocytes, myeloid progenitors, or low density granulocytes [30-32]. This could explain the moderate correlations we observe between $M P O$ and PRTN3 expression from total leukocytes and histone modifications at MPO and PRTN3 in purified neutrophils. Evidence from in situ hybridization [13] and comparison of expression with differential blood counts (manuscript in preparation) indicates AAV patients have increased expression of MPO and PRTN3 in peripheral neutrophils, but this does not exclude the contribution of other cell types to MPO and PRTN3 expression. Indeed, the differential expression of chromatin-modifying factors was identified in total leukocytes; therefore, it is possible that altered expression of these factors in patients with AAV could occur in other peripheral blood cells. We identified differential expression of EHMT1, EHMT2, and MSL1 in neutrophils, but we also detected reduced levels of EHMT1 and EHMT2 in monocytes. The increased expression of MSL1 in neutrophils of patients with AAV is consistent with the elevated levels of H4K16ac we 
detected at $M P O$ and PRTN3 in neutrophils from patients with active disease. Intriguingly, monocytes, which did not differentially expression MSL1 between patients and healthy controls, may regulate transcriptional activation through a different network of epigenetic regulators. Low density granulocytes could also have altered expression of these histone-modifying genes.

By extension, the pattern of histone modifications we identified in neutrophils at MPO and PRTN3 might occur in other cell types. In fact, publically available data from the Encyclopedia of DNA Elements (ENCODE) project corroborates enrichment of $\mathrm{H} 3 \mathrm{~K} 4 \mathrm{me} 2$ at the promoter and within the gene body of PRTN3 and MPO. Conversely, very little enrichment of $\mathrm{H} 3 \mathrm{~K} 27 \mathrm{me} 3$ at $M P O$ and PRTN3 is reported for monocytes. Depending on the cell type, the transcriptional output of these autoantigen genes in patients with active AAV may use similar but not identical chromatin regulatory mechanisms. Investigating epigenetic patterns of other myeloid lineages would further define transcriptional regulatory mechanisms during AAV.

\section{Heterogenous surface PR3 expression among neutrophils}

We report the level of specific histone modifications at autoantigen genes in samples of total circulating neutrophils; however, several reports have documented a subset of neutrophils with membrane bound PR3 (mPR3) and the surface glycoprotein CD177. The fraction of neutrophils positive for mPR3 and surface CD177 ranges from 0 to $100 \%$, is genetically determined and stable, and is elevated in patients with AAV [33-36]. It is conceivable that this subset of neutrophils could influence the level of a particular histone modification measured at autoantigen genes. For instance, the observation that histone modifications are more dramatically altered in patients with increased expression might also reflect patients with a larger percentage of mPR3 and CD177 positive neutrophils. However, separate reports have described conflicting results on whether mPR3 and CD177 positive neutrophils have elevated PRTN3 expression [37, 38]; thus, the association of a histone modification signature with increased autoantigen expression may not depend on mPR3 and surface CD177 positivity. In addition, PR3-ANCA has been shown to stimulate neutrophil activation regardless of mPR3 status [39]. This is consistent with the hypothesis that dysregulation of neutrophil transcriptional status, likely the result of epigenetic changes, predisposes neutrophils to activation.

\section{Limitations of current epigenetic analysis, and rationale for future epigenomic studies in patients with AAV}

Although the role epigenetic mechanisms play in AAV and other vasculitides is being investigated more intensively [40], challenges still remain. For instance, this study does not distinguish whether or not epigenetic changes are a consequence of AAV or are an integral component of AAV pathogenesis, and our patient samples prevented an investigation of the role of therapy on the chromatin status. However, our results provide a rationale for further investigating the role of epigenetic changes in AAV. Measuring the status of histone modifications longitudinally will more accurately assess the relationship of a histone signature with disease status. Genome-wide mapping of histone modifications will define chromosomal domains and genes within those domains with shared regulatory mechanisms. This is critical to identify potential chromatin regulatory networks that play a role in neutrophil activation in AAV. Coupled with data from genome-wide association studies epigenomic profiling in AAV, especially expanded to include other cell types, will inform potential function of genetic variants [41].

\section{Conclusions}

While additional questions remain to be answered, the close association of specific histone modifications with active AAV is consistent with the hypothesis that an epigenetic signature corresponds to disease status, and suggests that a dynamic epigenome is involved in the pathogenesis of AAV. Thus, in addition to the presence of autoantibodies, the plasticity of the epigenome may promote the development of AAV.

\section{Methods \\ Patients}

Patients with biopsy-proven anti-neutrophil cytoplasmic autoantibody (ANCA) systemic vasculitis or renallimited disease enrolled in this study were diagnosed between 1985 and 2013 and followed in the Glomerular Disease Collaborative Network (GDCN) [42, 43]. All study materials were given Institutional Review Board approval for human subjects (IRB study \#97-0523) by the University of North Carolina Office of Human Research Ethics. Study subjects gave informed, written consent and participated according to UNC IRB guidelines. A total of 122 patients with ANCA vasculitis and 71 healthy controls were included in this study. Patients were diagnosed according to the Chapel Hill Consensus Conference $[44,45]$. ANCA serotypes were determined by indirect immunofluorescence and/or antigen-specific proteinase (PR3) and myeloperoxidase (MPO) enzymelinked immune-absorbent assays (ELISA) [46]. Disease activity was determined using the 2003 Birmingham Vasculitis Activity Score (BVAS) [47]. Remission was defined as BVAS $=0$ and no clinical or laboratory evidence of active disease, and active disease was defined as a BVAS $\geq 3$ with clinical and/or laboratory evidence of disease. Among the ANCA cohort, 25 samples from 21 
patients were enrolled in a microarray study listed in Additional file 1: Table S1, 80 samples from 80 patients in a quantitative PCR study of total leukocytes listed in Additional file 2: Table S2, 22 samples (10 monocytes and 12 neutrophils) from 13 patients in a quantitative PCR study of purified cell types listed in Additional file 2: Table S2 (samples TM81-TM93), and 32 samples from 32 patients in several chromatin immunoprecipitation studies listed in Additional file 4: Table S3 and Additional file 6: Table S4. The tables in these Additional files include the following information for each patient: race, gender, age, diagnosis, ANCA subtype, disease status, BVAS, ANCA titer, serum creatinine, and treatment, WBC counts, and absolute neutrophil counts, if available.

\section{Microarray and quantitative RT-PCR}

RNA from circulating leukocytes was extracted using RNA STAT-60 (Tel-Test "B", Friendswood, TX, USA) and DNase treated. For the microarray study, 25 ANCApatient samples were compared to 16 healthy controls by Affymetrix microarray gene chip for identification of gene expression levels, as previously described $[13,15,48]$. Differentially expressed genes were identified by analysis of variance (ANOVA) using Partek Genomics Suite (Partek GS 6.4, St Louis, CA) with a 1.2-fold change and $p$ value $<0.05$ between patient and healthy control groups. Differentially expressed genes were analyzed using the Ingenuity Pathway Analysis (IPA; Java version 1.7.0_25 and 1.6.0_51; Ingenuity Systems, Redwood City, CA) to evaluate biological themes [49].

For quantitative RT-PCR, leukocyte RNA was analyzed from 40 PR3-ANCA patients and 40 MPO-ANCA patients (each group of 40: remission $(B V A S=0), n=20$; active (BVAS $\geq 3$ ), $n=20$ ), and 20 healthy controls. Quantitative detection of MPO and PRTN3 mRNA levels from patient samples was determined using a standard curve. The standard curve for $M P O$ mRNA levels was generated using HL60 cells, a cell positive for MPO mRNA, diluted with Jurkat cells, a cell line negative for MPO mRNA. The standard curve for PRTN3 mRNA levels was generated using THP-1 cells, a cell positive for PTRN3 mRNA, diluted with Jurkat cells, a cell line negative for PRTN3 mRNA. MPO and PRTN3 mRNA levels for patients and healthy donor samples were determined by $2^{-\Delta \Delta \mathrm{Ct}}$ calculations and expressed relative to standard curves. Primers and probes for $M P O$ and PRTN3 were previously published, and Cytochrome c oxidase $(C O X 5 B)$ was used as mRNA internal control [13]. Quantitative detection of EHMT1/GLP, EHMT2/ G9a, MSL1, and ING4 mRNA levels was determined by $2^{-\Delta \Delta C t}$ calculations, with $C O X 5 B$ as the mRNA internal control, and expressed as fold change of reference control samples. Primers and probes were purchased from
Applied Biosystems (Applied Biosystems, Foster City, CA). Quantitative RT-PCR assays were performed on an ABI PRISM 7900HT sequence detection system (Applied Biosystems), using the TaqMan EZ RT-PCR kit (Applied Biosystems).

\section{Monocyte and neutrophil isolation}

Peripheral blood was collected in two $10 \mathrm{ml}$ sodium heparin tubes (14-18 $\mathrm{ml}$ of blood). Red blood cells were depleted with 1 volume HetaSep (Stem Cell Technologies) for 5 volumes whole blood and centrifuged at 92g, $6 \mathrm{~min}$, no brake. The nucleated cells were layered on Histopaque 1077 (Sigma) and centrifuged (400g, $30 \mathrm{~min}$, no brake). PBMCs were washed once with PBS before isolating cell types using magnetic microbeads. CD14+ monocytes were isolated with the Human CD14 Positive Selection Kit as previously described (EasySep ${ }^{\text {tw }}$, Stem Cell Technologies) $[50,51]$. RNA was extracted from monocytes with the Qiagen AllPrep DNA/RNA Mini Kit (Qiagen, Chatsworth, CA). In parallel, neutrophils were isolated from the red blood cell/granulocyte pellet remaining after the Histopaque spin. The neutrophil pellet was washed once with PBS, and red cells were lysed with $5 \mathrm{ml}$ water followed by $5 \mathrm{ml} 2 \times$ PBS. Neutrophils were pelleted $(300 g, 10 \mathrm{~min})$, lysed with STAT-60 (Tel-Test "B", Friendswood, TX, USA), and RNA was extracted.

\section{Chromatin immunoprecipitation (ChIP)}

ChIP for H3K9me2 was previously described [15]. ChIP for H4K16ac and H3K4me2 followed a similar procedure with the following modifications: neutrophils were isolated by HetaSep (StemCell Technologies, Vancouver, BC, Canada). Cells $\left(5 \times 10^{6}\right.$ cells $/ \mathrm{ml} /$ sample $)$ were incubated with formaldehyde at a final concentration of $0.6 \%$ to crosslink DNA and proteins, and then lysed and sonicated in lysis buffer without SDS $(10 \mathrm{mM}$ Tris$\mathrm{HCl}, \mathrm{pH}$ 8.0; $100 \mathrm{mM} \mathrm{NaCl} ; 1 \mathrm{mM}$ EDTA, $\mathrm{pH}$ 8.0; 0.5 mM EGTA; $0.1 \%$ Na-Deoxycholate; $0.5 \% \mathrm{~N}$-Lauroylsarcosine). After sonication, lysate was diluted 1:1 in lysis buffer and Triton X-100 was added to $1 \%$ final concentration. Anti-H3K9me2 antibody was purchased from Abcam (Abcam, Cambridge, MA), and antiH3K4me2, H4K16ac, and H3K9,14ac antibodies from Millipore (EMD Millipore, Billerica, MA). Primers for Q-PCR of PRTN3 and MPO promoter regions and control MYO-D were previously published [15]. FCGR3B promoter, sense primer (CCACCATAGAACAGGAAT AG) and antisense primer (AGACCTTTGGGAGAGT AAA) were from Integrated DNA Technologies (Integrated DNA Technologies, Coralville, IA). Specific DNA was analyzed by quantitative PCR and expressed as a relative percent of input chromatin. The level of 
enrichment for the indicated histone modification was calculated using raw $\mathrm{Ct}$ values from qPCR of diluted input sample.

\section{Statistics}

Descriptive statistics include mean and standard deviation, or median and interquartile range for non-normal distributions. Differences between two groups were compared by Wilcoxon test. Spearman rank correlations were used. Analyses and plots were conducted with SAS software (Version 9.3) (SAS Institute, Cary, NC). Microarray data was analyzed by ANOVA using Partek GS 6.4. Dot plots and box and whisker plots in each figure were generated by Partek GS 6.4.

\section{Additional files}

Additional file 1: Table S1. Characteristics of patients with ANCA

Additional file 2: Table S2. Characteristics of patients with ANCA disease used to measure expression by TaqMan qRT-PCR. (PDF 65.3 kb)

Additional file 3: Figure S1. Comparison of therapy in patients during remission on expression of histone modifying genes, EHMT1, EHMT2, ING4, and MSL1. (PDF $93.6 \mathrm{~kb}$ )

Additional file 4: Table S3. Characteristics of patients with ANCA disease used for chromatin immunoprecipitation. (PDF $46.2 \mathrm{~kb}$ )

Additional file 5: Figure S2. ChIP for active histone modification H3K9,14 in neutrophils and cell lines. (PDF 167 kb)

Additional file 6: Table S4. Histone modifications profiled by chromatin immunoprecipitation for each patient. (PDF $41.9 \mathrm{~kb}$ )

\section{Acknowledgements}

We are grateful for the patients who enrolled in our studies and donated blood in support of the research.

\section{Funding}

This work was supported by federal grant P01 DK058335-06 (NIH/NIDDK).

\section{Availability of data and material}

The data that support the findings presented in this article are available from the corresponding author upon request.

\section{Authors' contributions}

JY conceived the study design, performed all experiments, interpreted experimental results, prepared figures, and contributed to writing the manuscript. HG performed experiments and contributed to figures. CJP maintained the patient database, and reviewed and compiled clinical data for all patients enrolled in the study included in Additional file 1: Table S1. SLH interpreted data for statistical analysis and supervised $\mathrm{YH}$. YH performed statistical analysis. BEJ isolated monocytes and neutrophils, purified RNA for expression analysis. CDH consented patients enrolled in the study, and collected and processed patient samples for analysis. EAM processed samples for analysis. WFP reviewed patient data, interpreted experimental results, and critically reviewed the manuscript. JCJ helped conceive the study design, interpreted experimental results, and critically reviewed the manuscript. RJF conceived the study design, reviewed patient data, interpreted experimental results, and critically reviewed the manuscript. DJC conceived the study design, performed experiments, interpreted experimental results, prepared figures, and wrote the manuscript. All authors reviewed the manuscript before submission.

\section{Competing interests}

The authors declare that they have no competing interest.

\section{Consent for publication}

All patient data was derived from samples collected from patients who gave informed, written consent, according to IRB guidelines approved by University of North Carolina Office of Human Research Ethics. The consent form, signed by all patients enrolled in the study, included the following description: "The specimens may be shared with researchers at this or other institutions. Research studies may be done at many places at the same time. Your personal identifying information will not be sent to other researchers. You will not be identified in any report or publication about research using your specimens."

\section{Ethics approval and consent to participate}

All study materials were given Institutional Review Board approval for human subjects (IRB study \#97-0523) by the University of North Carolina Office of Human Research Ethics. Study subjects gave informed, written consent and participated according to UNC IRB guidelines.

\section{Author details}

${ }^{1}$ UNC Kidney Center, Department of Medicine, Division of Nephrology and Hypertension, University of North Carolina at Chapel Hill, Chapel Hill, NC, USA. ${ }^{2}$ Department of Pathology and Laboratory Medicine, University of North Carolina at Chapel Hill, Chapel Hill, NC, USA. ${ }^{3}$ Department of Genetics, University of North Carolina at Chapel Hill, 120 Mason Farm Road, Campus Box 7264, Chapel Hill, NC 27599, USA. ${ }^{4}$ Department of Nephrology, The Second Affiliated Hospital, School of Medicine, Xian Jiaotong University, 157 Xiwu Road, Xian, Shaanxi 710004, People's Republic of China.

Received: 6 April 2016 Accepted: 2 August 2016

Published online: 12 August 2016

\section{References}

1. Falk RJ, Terrell RS, Charles LA, Jennette JC. Anti-neutrophil cytoplasmic autoantibodies induce neutrophils to degranulate and produce oxygen radicals in vitro. Proc Nat Acad Sci U S A. 1990;87(11):4115-9.

2. Little MA, Al-Ani B, Ren S, Al-Nuaimi H, Leite Jr M, Alpers CE, et al. Anti-proteinase 3 anti-neutrophil cytoplasm autoantibodies recapitulate systemic vasculitis in mice with a humanized immune system. PloS One. 2012;7(1), e28626.

3. Xiao H, Heeringa P, Hu P, Liu Z, Zhao M, Aratani Y, et al. Antineutrophil cytoplasmic autoantibodies specific for myeloperoxidase cause glomerulonephritis and vasculitis in mice. J Clin Invest. 2002;110(7):955-63.

4. Pfister $\mathrm{H}$, Ollert M, Frohlich LF, Quintanilla-Martinez L, Colby TV, Specks U, et al. Antineutrophil cytoplasmic autoantibodies against the murine homolog of proteinase 3 (Wegener autoantigen) are pathogenic in vivo. Blood. 2004; 104(5):1411-8.

5. Thai LH, Charles $P$, Resche-Rigon M, Desseaux K, Guillevin L. Are antiproteinase-3 ANCA a useful marker of granulomatosis with polyangiitis (Wegener's) relapses? Results of a retrospective study on 126 patients. Autoimmun Rev. 2014;13(3):313-8.

6. Cui Z, Zhao MH, Segelmark M, Hellmark T. Natural autoantibodies to myeloperoxidase, proteinase 3, and the glomerular basement membrane are present in normal individuals. Kidney Int. 2010;78(6):590-7.

7. Roth AJ, Ooi JD, Hess JJ, Van Timmeren MM, Berg EA, Poulton CE, et al. Epitope specificity determines pathogenicity and detectability in ANCAassociated vasculitis. J Clin Invest. 2013:123(4):1773-83.

8. Dobric S, Popovic D, Nikolic M, Andrejevic S, Spuran M, Bonaci-Nikolic B. Anti-neutrophil cytoplasmic antibodies (ANCA) specific for one or several antigens: useful markers for subtypes of ulcerative colitis and associated primary sclerosing cholangitis. Clin Chem Lab Med. 2012;50(3):503-9.

9. Csernok E, Ernst M, Schmitt W, Bainton DF, Gross WL. Activated neutrophils express proteinase 3 on their plasma membrane in vitro and in vivo. Clin Exp Immunol. 1994;95(2):244-50.

10. Kettritz R, Schreiber A, Luft FC, Haller H. Role of mitogen-activated protein kinases in activation of human neutrophils by antineutrophil cytoplasmic antibodies. J Am Soc Nephrol. 2001;12(1):37-46.

11. Yang JJ, Preston GA, Pendergraft WF, Segelmark M, Heeringa P, Hogan SL, et al. Internalization of proteinase 3 is concomitant with endothelial cell apoptosis and internalization of myeloperoxidase with generation of intracellular oxidants. Am J Pathol. 2001;158(2):581-92.

12. Schreiber A, Kettritz $R$. The neutrophil in antineutrophil cytoplasmic autoantibody-associated vasculitis. J Leukoc Biol. 2013;94(4):623-31. 
13. Yang JJ, Pendergraft WF, Alcorta DA, Nachman PH, Hogan SL, Thomas RP, et al. Circumvention of normal constraints on granule protein gene expression in peripheral blood neutrophils and monocytes of patients with antineutrophil cytoplasmic autoantibody-associated glomerulonephritis. J Am Soc Nephrol. 2004;15(8):2103-14.

14. Cowland JB, Borregaard $\mathrm{N}$. The individual regulation of granule protein mRNA levels during neutrophil maturation explains the heterogeneity of neutrophil granules. J Leukoc Biol. 1999;66(6):989-95.

15. Ciavatta DJ, Yang J, Preston GA, Badhwar AK, Xiao H, Hewins P, et al. Epigenetic basis for aberrant upregulation of autoantigen genes in humans with ANCA vasculitis. J Clin Invest. 2010;120(9):3209-19.

16. Smith ER, Cayrou C, Huang R, Lane WS, Cote J, Lucchesi JC. A human protein complex homologous to the Drosophila MSL complex is responsible for the majority of histone $\mathrm{H} 4$ acetylation at lysine 16. Mol Cell Biol. 2005;25(21):9175-88

17. Mathema VB, Koh YS. Inhibitor of growth-4 mediates chromatin modification and has a suppressive effect on tumorigenesis and innate immunity. Tumour Biol. 2012;33(1):1-7.

18. Doyon Y, Cayrou C, Ullah M, Landry AJ, Cote V, Selleck W, et al. ING tumor suppressor proteins are critical regulators of chromatin acetylation required for genome expression and perpetuation. Mol Cell. 2006;21(1):51-64.

19. Nozell S, Laver T, Moseley D, Nowoslawski L, De Vos M, Atkinson GP, et al. The ING4 tumor suppressor attenuates NF-kappaB activity at the promoters of target genes. Mol Cell Biol. 2008;28(21):6632-45.

20. Kurz T, Weiner M, Skoglund C, Basnet S, Eriksson P, Segelmark M. A myelopoiesis gene signature during remission in ANCA associated vasculitis does not predict relapses but seems to reflect ongoing prednisolone therapy. Clin Exp Immunol. 2014;175(2):215-26.

21. Bernstein BE, Mikkelsen TS, Xie X, Kamal M, Huebert DJ, Cuff J, et al. A bivalent chromatin structure marks key developmental genes in embryonic stem cells. Cell. 2006;125(2):315-26.

22. Azuara V, Perry P, Sauer S, Spivakov M, Jorgensen HF, John RM, et al. Chromatin signatures of pluripotent cell lines. Nat Cell Biol. 2006;8(5):532-8.

23. Weishaupt H, Sigvardsson M, Attema JL. Epigenetic chromatin states uniquely define the developmental plasticity of murine hematopoietic stem cells. Blood. 2010;115(2):247-56.

24. Barski A, Cuddapah S, Cui K, Roh TY, Schones DE, Wang Z, et al. Highresolution profiling of histone methylations in the human genome. Cell. 2007;129(4):823-37.

25. Bazzoni F, Cassatella MA, Rossi F, Ceska M, Dewald B, Baggiolini M. Phagocytosing neutrophils produce and release high amounts of the neutrophil-activating peptide 1/interleukin 8. J Exp Med. 1991;173(3):771-4.

26. Lord PC, Wilmoth LM, Mizel SB, Mccall CE. Expression of interleukin-1 alpha and beta genes by human blood polymorphonuclear leukocytes. J Clin Invest. 1991;87(4):1312-21.

27. Newburger PE, Subrahmanyam YV, Weissman SM. Global analysis of neutrophil gene expression. Curr Opin Hematol. 2000;7(1):16-20.

28. Tsukahara $Y$, Lian Z, Zhang X, Whitney C, Kluger Y, Tuck D, et al. Gene expression in human neutrophils during activation and priming by bacterial lipopolysaccharide. J Cell Biochem. 2003;89(4):848-61.

29. Yang JJ, Preston GA, Alcorta DA, Waga I, Munger WE, Hogan SL, et al. Expression profile of leukocyte genes activated by anti-neutrophil cytoplasmic autoantibodies (ANCA). Kidney Int. 2002;62(5):1638-49.

30. Cheadle C, Berger AE, Andrade F, James R, Johnson $K$, Watkins $T$, et al. Transcription of proteinase 3 and related myelopoiesis genes in peripheral blood mononuclear cells of patients with active Wegener's granulomatosis. Arthritis Rheum. 2010;62(6):1744-54.

31. Ohlsson S, Hellmark T, Pieters K, Sturfelt G, Wieslander J, Segelmark M. Increased monocyte transcription of the proteinase 3 gene in small vessel vasculitis. Clin Exp Immunol. 2005;141(1):174-82.

32. Grayson PC, Carmona-Rivera C, Xu L, Lim N, Gao Z, Asare AL, et al. Neutrophilrelated gene expression and low-density granulocytes associated with disease activity and response to treatment in antineutrophil cytoplasmic antibodyassociated vasculitis. Arthritis Rheumatol. 2015;67(7):1922-32.

33. Halbwachs-Mecarelli L, Bessou G, Lesavre P, Lopez S, Witko-Sarsat V. Bimodal distribution of proteinase 3 (PR3) surface expression reflects a constitutive heterogeneity in the polymorphonuclear neutrophil pool. FEBS Lett. 1995; 374(1):29-33.

34. Schreiber A, Busjahn A, Luft FC, Kettritz R. Membrane expression of proteinase 3 is genetically determined. J Am Soc Nephrol. 2003;14(1):68-75.
35. Von Vietinghoff S, Tunnemann G, Eulenberg C, Wellner M, Cristina Cardoso M, Luft FC, et al. NB1 mediates surface expression of the ANCA antigen proteinase 3 on human neutrophils. Blood. 2007;109(10):4487-93.

36. Witko-Sarsat V, Lesavre P, Lopez S, Bessou G, Hieblot C, Prum B, et al. A large subset of neutrophils expressing membrane proteinase 3 is a risk factor for vasculitis and rheumatoid arthritis. J Am Soc Nephrol. 1999;10(6): 1224-33.

37. Abdgawad M, Gunnarsson L, Bengtsson AA, Geborek P, Nilsson L, Segelmark $M$, et al. Elevated neutrophil membrane expression of proteinase 3 is dependent upon CD177 expression. Clin Exp Immunol. 2010;161(1):89-97.

38. Hu N, Mora-Jensen H, Theilgaard-Monch K, Doornbos-Van Der Meer B, Huitema MG, Stegeman CA, et al. Differential expression of granulopoiesis related genes in neutrophil subsets distinguished by membrane expression of CD177. PloS One. 2014;9(6):e99671.

39. Hu N, Westra J, Huitema MG, Bijl M, Brouwer E, Stegeman CA, et al. Coexpression of CD177 and membrane proteinase 3 on neutrophils in antineutrophil cytoplasmic autoantibody-associated systemic vasculitis: antiproteinase 3-mediated neutrophil activation is independent of the role of CD177-expressing neutrophils. Arthritis Rheum. 2009;60(5):1548-57.

40. Renauer P, Coit P, Sawalha AH. Epigenetics and vasculitis: a comprehensive review. Clin Rev Allergy Immunol. 2016;50(3):357-66.

41. Sawalha $A H$, Dozmorov MG. Epigenomic functional characterization of genetic susceptibility variants in systemic vasculitis. J Autoimmun. 2016;67:76-81.

42. Hogan SL, Falk RJ, Chin H, Cai J, Jennette CE, Jennette JC, et al. Predictors of relapse and treatment resistance in antineutrophil cytoplasmic antibodyassociated small-vessel vasculitis. Ann Intern Med. 2005:143(9):621-31.

43. Pagnoux C, Hogan SL, Chin H, Jennette JC, Falk RJ, Guillevin L, et al. Predictors of treatment resistance and relapse in antineutrophil cytoplasmic antibody-associated small-vessel vasculitis: comparison of two independent cohorts. Arthritis Rheum. 2008:58(9):2908-18.

44. Falk RJ, Gross WL, Guillevin L, Hoffman GS, Jayne DR, Jennette JC, et al. Granulomatosis with polyangiitis (Wegener's): an alternative name for Wegener's granulomatosis. Arthritis Rheum. 2011;63(4):863-4

45. Jennette JC, Falk RJ, Bacon PA, Basu N, Cid MC, Ferrario F, et al. 2012 revised International Chapel Hill Consensus Conference Nomenclature of Vasculitides. Arthritis Rheum. 2013;65(1):1-11.

46. Hagen EC, Ballieux BE, Van Es LA, Daha MR, Van Der Woude FJ. Antineutrophil cytoplasmic autoantibodies: a review of the antigens involved, the assays, and the clinical and possible pathogenetic consequences. Blood. 1993;81(8):1996-2002.

47. Luqmani RA, Bacon PA, Moots RJ, Janssen BA, Pall A, Emery P, et al. Birmingham Vasculitis Activity Score (BVAS) in systemic necrotizing vasculitis. QJM. 1994:87(11):671-8.

48. Alcorta DA, Barnes DA, Dooley MA, Sullivan P, Jonas B, Liu Y, et al. Leukocyte gene expression signatures in antineutrophil cytoplasmic autoantibody and lupus glomerulonephritis. Kidney Int. 2007;72(7):853-64.

49. Cao Y, Yang J, Colby K, Hogan SL, Hu Y, Jennette CE, et al. High basal activity of the PTPN22 gain-of-function variant blunts leukocyte responsiveness negatively affecting $\mathrm{IL}-10$ production in ANCA vasculitis. PloS One. 2012;7(8), e42783.

50. Lyons PA, Koukoulaki M, Hatton A, Doggett K, Woffendin HB, Chaudhry AN, et al. Microarray analysis of human leucocyte subsets: the advantages of positive selection and rapid purification. BMC Genomics. 2007:8:64.

51. Zilbauer M, Rayner TF, Clark C, Coffey AJ, Joyce CJ, Palta P, et al. Genomewide methylation analyses of primary human leukocyte subsets identifies functionally important cell-type-specific hypomethylated regions. Blood. 2013;122(25):e52-60. 